\title{
Miscellany
}

\begin{abstract}
Awards
Alfred Meyer Memorial Award

The first Alfred Meyer Memorial Award will be made to Professor Brian Meldum of the Department of Neurology, Institute of Psychiatry, London, for his work on the analysis of the pathological and pharmacological basis of the hippocampal damage in epilepsy.

Professor Meldrum's lecture entitled The Cause and Effects of Epileptic Brain Damage' will take place in the Barnes Hall of the Royal Society of Medicine, London WC1M 8AE at 6.00 p.m. on 4 January 1995 when the presentation of the medal by the President of the British Neuropathological Society will be made. The lecture will be open to all. Further information: The Secretary of the British Neuropathological Society, Dr Janice Anderson, Addenbrookes Hospital, Cambridge CB2 298.
\end{abstract}

\section{Psychotherapy Research Initiative}

The Mental Health Foundation is launching an initiative to encourage specific research proposals that will develop methods for the evaluation of psychological therapies. In particular, three areas have been identified: core battery of change measures, therapist competencies, and health care economics. The maximum award will be $£ 80,000$ and projects may be for a period of up to three years. The first awards will be made in May 1995 and the closing date for applications will be 1 February 1995. Please write for the necessary guidelines and application forms, quoting 'Psychotherapy Research Initiative', to the Research Administrator, The Mental Health Foundation, 37 Mortimer Street, London WIN 7RJ.

\section{Whitbread Volunteer Action Award}

The 1993 Whitbread Volunteer Action Award was won by Lilian Baker who supports a group called Advocacy in Wirral which looks after the interests of people with mental health difficulties. Nomination forms for the awards, now in their 12th year, are avallable by writing to Whitbread Volunteer Action Awards, Freepost LOL 1936, Luton, Beds LU1 3YR (no stamp required) or calling 0582397759.

\section{New publications}

Single copies of the leaflet Looking After Your Money in Hospital: information for people who spend a long time in hospital are available free, and bulk copies on request, from: Age Concern England, 1286 London Road, London SW 16 4ER (telephone 081679 8000).

The Health and Safety Commission (HSC) has published Rationalisation of Risk Assessment and Other Common Provisions in Health and Safety Legislation, DD194, an HSC discussion document which is avallable free from HSE Books, PO Box 1999, Sudbury, Suffolk C10 6FS (telephone 0787 881165; fax 0787 313995). HSC's Review of Health and Safety Regulation is also available from HSE Books, price $£ 16.50$.

\section{HIV \& AIDS educational pack}

The Department of Health has produced HIV \& AIDS: the issues for hospital doctors. It is an educational pack for non specialist doctors about the ethical, social and legal issues surrounding the care and management of HIV/AIDS. It contains nine educational modules, including one entitled 'Psychiatric Case', each of which contains a case history and relevant information sheets summarised on acetate for group discussion. The tenth module is a resource pack containing relevant guidance on HIV/AIDS. The pack is available in postgraduate medical libraries and the material is able to be photocopied for teaching purposes.

\section{New grant for professionals working with refugees}

The Mental Health Foundation has announced that it has allocated a new grant of $\$ 32,000$ to the Refugee Support Centre, based in Stockwell, South London, to set up a training service targeted at professionals working with refugees. The intention of the Refugee Support Centre's training service is to increase awareness and to help professionals cope better with the mental health symptoms presented by refugees on arrival in the UK and during their period of exile. 